\title{
Influence of catechin on precipitation of aluminum hydroxide
}

\author{
Yue Ming Chen ${ }^{a}$, Ming Kuang Wang a,*, Pan Ming Huang ${ }^{b}$, Tsung Ming Tsao ${ }^{a}$, Kuo Chuan Lin ${ }^{c}$ \\ a Department of Agricultural Chemistry, National Taiwan University, Taipei 106, Taiwan \\ ${ }^{\mathrm{b}}$ Department of Soil Science, University of Saskachewan, 51 Campus Drive, Saskatoon, SK, Canada S7N 5A8 \\ c Division of Silviculture, Taiwan Forestry Research Institute, COA, Taipei 10017, Taiwan
}

\section{A R T I C L E I N F O}

Article history:

Received 17 March 2008

Received in revised form 11 June 2009

Accepted 22 June 2009

Available online 28 July 2009

Keywords:

Aluminum hydroxide

$(+)$-Catechin

Al hydrolysis

Complexing and hampering

\begin{abstract}
A B S T R A C T
Polyphenols (catechins) are vital biomolecules in tea plants, Camellia sinensis, which are well adapted to acid soils with high availability of phytotoxic Al species. Since the mechanism of Al resistance in tea plants by catechin remains obscure, this study investigates the influence of catechin on aluminum transformation. It is found that the $\mathrm{pH}$ of the suspensions decreased with aging. The hydrolytic precipitates of Al were subjected to surface area, X-ray diffraction (XRD), Fourier-transform infrared absorption spectroscopy (FT-IR), transmission electron microscopy (TEM), thermal, and chemical analyses. At the initial Al concentration of $2 \times 10^{-2} \mathrm{M}$ sample, in the absence of catechin for 180 - $\mathrm{d}$ aging, only $59.7 \%$ of the $\mathrm{Al}$ is remained in the filtrate, including readily, moderately extractable and nonextractable fractions. However, in the presence of catechin, above $70.5 \%$ of the $\mathrm{Al}$ is present in the filtrate. The readily, moderately extractable and nonextractable $\mathrm{Al}$ fractions with 8-quinolinolate method are decreased with increasing concentrations of catechin after 180-d aging. Specific surface area of the $\mathrm{Al}$ precipitates increases with increasing concentrations of catechin. In the absence of catechin, the Al precipitates with prolonged aging are mostly crystalline gibbsite. X-ray diffraction analysis and TEM observations also show the structural distortion within the hydrolytic precipitates of $\mathrm{Al}$ in the presence of catechin. FT-IR spectra show that catechin substantially inhibits the formation of crystalline aluminum hydroxides. X-ray noncrystalline to poor-ordered hydrolytic reaction products of Al are formed in the presence of catechin. TEM images also show that the Al precipitates form under the perturbation of catechin are fine, shapeless and hollow colloids that are deformed and aggregated. Thermal analysis shows that the hydrolytic reaction products of $\mathrm{Al}$ lost their structural water gradually when catechin concentration is raised from $0 \mathrm{M}$ (control) to $4.0 \times 10^{-3} \mathrm{M}$, indicating that greater structural disorder occurs with increasing catechin concentration in the $\mathrm{Al}$ systems.
\end{abstract}

Crown Copyright @ 2009 Published by Elsevier B.V. All rights reserved.

\section{Introduction}

Aluminum can be released from aluminosilicate minerals into soil solution due to the acidity generated by natural and anthropogenic processes. High reactivity of Al leads to hydrolytic reactions and to strong complexation with naturally occurring organic acids commonly present in soils (Huang, 1988; Vance et al., 1996; Sanabria et al., 2008). The relative distribution of the hydrolyzed and complexed $\mathrm{Al}$ species is determining factor for Al mobility in soil solution and toxicity to natural ecosystems (Bertsch and Parker, 1996). Aluminum can be polymerized into various polynuclear species. Aluminum salt solutions are neutralized with a base, the hydrolysis of Al results in the initial formation of amorphous and poorly crystalline Al hydroxide, which will subsequently transform into crystallized Al hydroxides upon aging. There are three polymorphs of Al hydroxides, by gibbsite, bayerite and nondstrandite (Wang et al., 2003). Their crystal structures vary only in the arrangements of the stacking sequences of $\mathrm{Al}(\mathrm{OH})_{3}$ layers. However, the formation of crystalline or noncrystal-

\footnotetext{
* Corresponding author. Tel.: +88611886233664808 (0); fax: +8861188622366 0751 E-mail address: mkwang@ntu.edu.tw (M.K. Wang).
}

line Al hydroxides is influenced by the ionic environment in the systems. For instance, chloride (Turner and Ross, 1970) and sulfate (Hsu, 1973) at high concentrations, silicic acid (Luciuk and Huang, 1974) and tannic acid (Colombo et al., 2004; Yu et al., 2006, 2007), inhibit the formation of crystalline Al hydroxides.

The chemistry of Al transformation as influenced by organic acids common in soils and sediments has been well documented (Kwong and Huang, 1977; Kodama and Schnitzer, 1980; Kwong and Huang, 1981; Huang et al., 2002; Colombo et al., 2004; Yu et al., 2006, 2007; Hu et al., 2008). Catechin is a vital biomolecule in tea plants which are well adapted to acid soils with high availability of phytotoxic $\mathrm{Al}$ species. However, the influence of catechin on the transformation of $\mathrm{Al}$ remains to be uncovered.

Natural organic matter (NOM) has a profound effect on the availability of nutrients for plant growth. Organic matter can be mineralized by soil microorganisms to release $\mathrm{N}, \mathrm{P}$ and $\mathrm{S}$. Organic matter also influences the supply of nutrients from other sources. Furthermore, organic substances in soil can exert physiological effects on plant growth. Many studies have also shown that some compounds such as polyphenols are present in crop residues and soils (Whitehead, 1964; Wang et al., 1971; Vrsalovic et al., 2005). 
Catechins have been considered to have significant beneficial effects on human health. Catechins such as $(+)$-catechin $(C),(-)-$ epicatechin (EC), (-)-epigallocatechin (EGC), (-)-epicatechin gallate (ECG) and (-)-epigallocatechin gallate (EGCG), have recently received much attention as protective agents against cardiovascular disease and cancer (Dubey et al., 2002; Kim et al., 2003). It is generally believed that catechins, the principal bioactive compounds in tea, are responsible for the claimed therapeutic activities of tea. Polyphenols have high reactivity toward other phenolic or metal compounds, giving rise to compounds with complicated structures (Chen et al., 2006). These transformations affect sensory properties such as color and taste (Cheynier et al., 1988).

The high Al affinity of complexed phenolics has been recognized by analytical chemists (Roser et al., 2005). However, in natural systems, catechins are part of the environmental chemicals and their influence on the hydrolytic reaction of $\mathrm{Al}$ is not well understood. This study investigates the influence of catechin on aluminum transformation.

\section{Materials and methods}

\subsection{Materials}

(+)-Catechin was obtained from the Sigma Chemical Co (St. Louis, MO) and used without further purification. Aluminum chloride was supplied from Merck (DAC, USP). Double deionized water (DDW) was purified with a Milli-Q water system (Millipore, Bedford, MA) prior to use.

\subsection{Methods}

Solutions containing $100 \mathrm{~mL}$ of $0.1 \mathrm{M} \mathrm{AlCl}_{3}$ were titrated to $\mathrm{OH} / \mathrm{Al}$ molar ratio of 2.5 with $0.1 \mathrm{M} \mathrm{NaOH}$ in the absence and in the presence of catechin. In suspensions, $\mathrm{Al}$ concentrations at final volume were $2 \times 10^{-2} \mathrm{M}$. The concentrations of catechin in the suspensions were 0 , $1.0 \times 10^{-4}$ and $4.0 \times 10^{-3} \mathrm{M}$, respectively. All solutions were then aged at $25{ }^{\circ} \mathrm{C}$ for $0,1,7,30$, and $180-\mathrm{d}$. After each aging period, the $\mathrm{pH}$ of each suspension was measured. At the end of 180-d aging, each suspension was separated into its filtrate and precipitate phases by ultrafiltration through a $0.025 \mu \mathrm{m}$ Millipore filter.

\subsection{Examination of the filtrates}

At the end of the selected aging periods, concentrations of the readily extractable, moderately extractable, and nonextactable Al were determined by the 8-quionlinolate method in the filtrate (i.e., $<0.025 \mu \mathrm{m}$ Millipore filter) (Turner, 1969). The terms "readily extractable" and "moderately extractable" $\mathrm{Al}$ as used here refer to $\mathrm{Al}$ extractable by 8 -quionlinolate chemicals within shaking periods of $10 \mathrm{~s}$ and $30 \mathrm{~min}$, respectively. The Al which cannot be extracted by 8quionlinolate within $30 \mathrm{~min}$ is referred to as nonextractable $\mathrm{Al}$ fractions. The total $\mathrm{Al}$ in the filtrate was determined after digestion with a mixture of $\mathrm{HNO}_{3}$ and $\mathrm{HCl}$ solution (Lim and Jackson, 1982). Amount of $\mathrm{Al}$ in the precipitate phase $(>0.025 \mu \mathrm{m})$ was calculated by the difference between the initial $\mathrm{Al}$ concentration (i.e., $2 \times 10^{-2} \mathrm{M}$ ) and the concentration of $\mathrm{Al}$ in the filtrate at the end of each aging period. The $\mathrm{pH}$ levels of the suspensions at the end of each aging period were measured using a Radiometer $\mathrm{pH}$ M83 $\mathrm{pH}$ meter.

\subsection{Examination of hydrolytic products of aluminum}

Samples of the precipitate phase were characterized by specific surface area, X-ray diffraction analysis (XRD), Fourier-transform infrared absorption spectrometry (FT-IR), transmission electron microscopy (TEM), and thermogravimetrics (TGA).
Specific surface area: Specific surface area was performed on $100 \mathrm{mg}$ of precipitates using the Teller (BET) equation with a Nova 2000 analyzer (Quanta Chrome).

$X$-ray diffraction $(X R D)$ analysis: The precipitates were examined by XRD using $\mathrm{CuK} \alpha$ radiation on a Rigaku Geigerflex X-ray diffractometer equipped with graphite monochromator, operating at $35 \mathrm{KV}$ and $15 \mathrm{~mA}$ at a step-scan of $0.02^{\circ} 2 \theta / \mathrm{s}$. The X-ray patterns were recorded in the range of $3-50^{\circ} 2 \theta$.

Fourier-transform infrared absorption spectrometry (FT-IR) analysis: $1 \mathrm{mg}$ of the precipitates dried in a vacuum desiccator was ground and mixed thoroughly with $200 \mathrm{mg}$ of oven-dried $\mathrm{KBr}$ powder of analytical regent (Merck, DAC, USP). The powder was placed in a die and compressed into a transparent disk. The infrared spectra were recorded by using a Perkin-Elmer System 2000 double beam infrared spectrophotometer. The spectral resolution was $4 \mathrm{~cm}^{-1}$.

Transmission electron microscopy (TEM) analysis: One drop of suspension was dried on a carbon-coated film on copper grids (3.05 $\mathrm{mm}$ in diameter), and then examined under a JEOL TEM (JEM $100 \mathrm{CXII}$ ) operated at $100 \mathrm{kV}$ for selected area electron diffraction (SAED).

Thermogravimetric analysis (TGA): About $12 \mathrm{mg}$ of air-dried samples were heated in a Fisher 260 furnace which was programmed to raise the temperature from 25 to $1000{ }^{\circ} \mathrm{C}$ at a rate of $10^{\circ} \mathrm{min}^{-1}$. The weight loss during heating was recorded by a Cahn RG automatic electrobalance. The DTG patterns were obtained from the TGA analysis.

\subsection{Statistical analyses}

Statistical data were analyzed using analysis of variance (ANOVA). Duncan's Multiple Range Test was used in all experiments to test the differences amongst the means at $p<0.05$.

\section{Results}

\section{1. $\mathrm{pH}$ of suspensions}

The suspension $\mathrm{pH}$ decreased with increasing aging days (Table 1 ). However, in the presence of cetechin, pH levels are slightly decreased with prolonged aging. This is attributed to not only Al complexing with catechin but $\mathrm{Al}$ also performs to the development of the proton acceptors in the Al precipitates.

3.2. Percentage distribution of Al that is readily, moderately extractable and nonextractable fractions $(<0.025 \mu \mathrm{m})$

After 180-d aging in the absence of catechin, about 59.7\% (22.1+ $30.5+7.1 \%)$ to the initial $\mathrm{Al}$ concentration is present in the filtrate, which is included readily, moderately extractable and nonextractable Al fractions (Table 2). However, in the presence of catechin, above $70.5 \%(20.3+42.2+8.0 \%)$ to the initial Al concentration is present in the filtrate. This is ascribed to the complexation of hydroxyl-Al by catechin perturbing the Al precipitation reaction. The fractions of moderately extractable and nonextractable $\mathrm{Al}$ are higher in the presence of catechin.

\section{Table 1}

The suspensions $\mathrm{pH}$ at initial $\mathrm{Al}$ concentration of $2.0 \times 10^{-2} \mathrm{M}$ as functions at different aging days, in the absence and presence of catechin $(\mathrm{OH} / \mathrm{Al}$ molar ratio $=2.5)$.

\begin{tabular}{llll}
\hline & \multicolumn{3}{l}{ Initial catechin concentration $(\mathrm{M})$} \\
\hline Aging day & 0 & $1.0 \times 10^{-4}$ & $4.0 \times 10^{-3}$ \\
0 & $5.50 \pm 0.05$ & $5.50 \pm 0.04$ & $5.50 \pm 0.04$ \\
1 & $5.48 \pm 0.04$ & $5.47 \pm 0.05$ & $5.40 \pm 0.05$ \\
7 & $5.15 \pm 0.05$ & $5.41 \pm 0.03$ & $5.34 \pm 0.06$ \\
30 & $4.62 \pm 0.03$ & $5.23 \pm 0.05$ & $5.24 \pm 0.04$ \\
180 & $4.08 \pm 0.04$ & $5.13 \pm 0.06$ & $5.12 \pm 0.05$ \\
\hline
\end{tabular}


Table 2

Percentage of the precipitated $\mathrm{Al}$ and the readily, moderately extractable and nonextractable $\mathrm{Al}$ fractions (\%), at initial $\mathrm{Al}$ concentrations of $2.0 \times 10^{-2} \mathrm{M}$ as influenced by catechin concentrations after $180-\mathrm{d}$ aging $(\mathrm{OH} / \mathrm{Al}$ molar ratio $=2.5)$.

\begin{tabular}{lrcc}
\hline Forms of $\mathrm{Al}^{+}$ & \multicolumn{1}{c}{0} & $1.0 \times 10^{-4} \mathrm{M}$ & $4.0 \times 10^{-3} \mathrm{M}$ \\
\hline *Readily extractable $\mathrm{Al}^{\ddagger}$ & $22.1 \pm 0.8$ & $20.3 \pm 1.1$ & $29.2 \pm 1.5$ \\
Moderately extractable $\mathrm{Al}^{\ddagger}$ & $30.5 \pm 1.3$ & $42.2 \pm 0.9$ & $33.4 \pm 1.0$ \\
Nonextractable $\mathrm{Al}^{\ddagger}$ & $7.1 \pm 0.7$ & $8.0 \pm 0.8$ & $14.1 \pm 1.2$ \\
Precipitated $\mathrm{Al}^{*}$ & $40.3 \pm 1.4$ & $29.5 \pm 0.5$ & $23.3 \pm 1.6$ \\
\hline
\end{tabular}

+ The suspensions was filtered through Millipore membrane with the pore size of $0.025 \mu \mathrm{m}$.

$¥$ Fractionation of solution $\mathrm{Al}$ speciation, i.e., readily extractable, moderately extractable and nonextractable Al was based on Turner (1969).

* Least significant difference (LSD, $p \leq 0.05$ ) of Al precipitated (\%) is 2.0 .

\subsection{Percentage distribution of $\mathrm{Al}$ in the phase of precipitates $(>0.025 \mu \mathrm{m})$}

The amount of $\mathrm{Al}$ in the phase of precipitates $(>0.025 \mu \mathrm{m})$ after 180-d aging decreases with increasing catechin concentrations (Table 2). Catechin hinder the hydrolytic reaction of Al. In the absence of catechin, $40.3 \%$ of the initial $\mathrm{Al}$ was precipitated. The addition of $1.0 \times 10^{-4} \mathrm{M}$ catechin to the same system reduced the $\mathrm{Al}$ precipitated to $29.5 \%$ at the end of the $180-\mathrm{d}$ aging. The precipitation of $\mathrm{Al}$ fraction was further decreased to $23.3 \%$ when the initial concentration of catechin was raised to $4 \times 10^{-3} \mathrm{M}$.

\subsection{Specific surface area of Al precipitates}

Specific surface area of Al precipitates increase with increasing the initial catechin concentration after 180-d aging (Table 3). The data clearly show that increasing the catechin concentration caused greater structural distortions within the $\mathrm{Al}$ precipitates, thus increasing the specific surface area.

\subsection{X-ray diffractograms $(X R D)$ of the precipitate phase}

In the absence of catechin, the reaction products after 180-d aging are mostly crystalline gibbsite (Fig. 1a). However, in the presence of catechin (i.e., $1 \times 10^{-4}$ and $4 \times 10^{-3} \mathrm{M}$ ) at the same initial $\mathrm{OH} / \mathrm{Al}$ molar ratio and $\mathrm{Al}$ concentration, the hydrolytic reaction products are XRD noncrystalline materials (Fig. 1b and c).

\subsection{FT-IR spectra of Al precipitates}

The wavenumber of FT-IR spectra in the absence of catechin at 3620, 3521 and 3469 are assigned to gibbsite (Table 4). The IR absorption bands at 3472,1639, 1072 and $570 \mathrm{~cm}^{-1}$ are assigned to stretching vibration of the $\mathrm{OH}$ bond, bending modes of the $\mathrm{H}_{2} \mathrm{O}, \mathrm{Al}-\mathrm{O}$ bond and $\mathrm{Al}-\mathrm{O}$ stretch $\left(\mathrm{AlO}_{6}\right)$ (Meher et al., 2005). On the other hand, the IR absorption bands at 3620, 3527, 3488, 1023 and $561 \mathrm{~cm}^{-1}$ are absent in the presence of catechin. This indicates that $\mathrm{Al}$ complexes with catechin, cause the loss of some function groups in the IR spectra of the precipitates.

Table 3

Influence of catechin on the specific surface area of $\mathrm{Al}$ precipitates after 180-d aging.

\begin{tabular}{ll}
\hline Catechin concentration $(\mathrm{M})$ & Specific surface area $\left(\mathrm{m}^{2} / \mathrm{g}\right)$ \\
\hline 0 & $13 \pm 1.1$ \\
$1.0 \times 10^{-4} \mathrm{M}$ & $25 \pm 1.5$ \\
$4.0 \times 10^{-3} \mathrm{M}$ & $47 \pm 1.3$ \\
$*$ LSD $(p \leq 0.05)$ & 1.7 \\
\hline
\end{tabular}

*LSD: least significant difference.
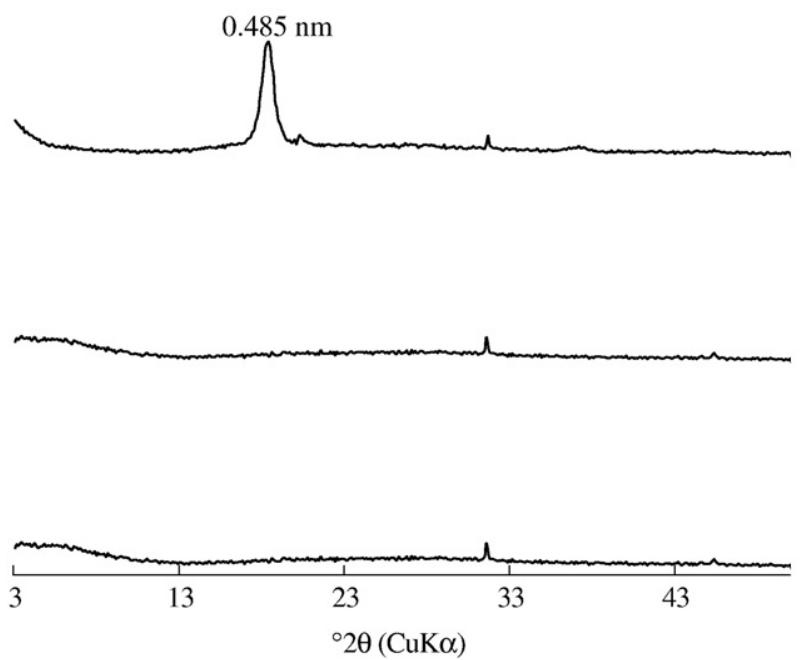

Fig. 1. X-ray diffractograms of Al precipitates at initial Al concentration of $2.0 \times 10^{-2} \mathrm{M}$ and $\mathrm{OH} / \mathrm{Al}$ molar ratio of 2.5: (a) in the absence of catechin, (b) in the presence of $1.0 \times 10^{-4} \mathrm{M}$ catechin, and (c) in the presence of $4.0 \times 10^{-3} \mathrm{M}$ catechin after 180-d aging.

\subsection{Surface morphology of Al precipitates}

In the absence of catechin, the Al precipitates are gibbsite (hexagonal plates) (Fig. 2a and b). This is supported by the XRD (Fig. 1a) and selected area electron diffraction pattern (SAED) (data not shown). In contrast, in the presence of $4.0 \times 10^{-3} \mathrm{M}$ catechin, the Al precipitates are noncrystalline to XRD (Fig. 1b and c) and SAED. They are fine, shapeless and hollow colloids that are deformed and aggregated. The sizes of the aggregate materials range from $0.5 \mu \mathrm{m}$ to $2 \mu \mathrm{m}$ (Fig. 2c and d).

\subsection{Thermal analysis}

The hydrolytic precipitation products of $\mathrm{Al}$ form in the absence of catechin lost the structural water at the critical temperature $\left(80^{\circ}-\right.$ $110{ }^{\circ} \mathrm{C}$ ) as indicated by the intense peak (Fig. 3a). The loss of the structural water of the $\mathrm{Al}$ precipitates form at the initial catechin concentration of $1.0 \times 10^{-4} \mathrm{M}$ is much lower (Fig. 3b) compared to the Al precipitates form in the absence of catechin (Fig. 3a). By contrast, the former lost much more adsorbed water than the latter. As the initial catechin concentration is increased to $4.0 \times 10^{-3} \mathrm{M}$, the loss of

Table 4

Assignment of FT-IR spectra at $\mathrm{OH} / \mathrm{Al}$ molar ratio $=2.5$ after $180-\mathrm{d}$ aging.

\begin{tabular}{|c|c|c|c|}
\hline $\begin{array}{l}\text { Catechin } \\
\text { concentration }\end{array}$ & $\begin{array}{l}\text { Wavenumber of } \\
\text { IR spectra }\end{array}$ & $\begin{array}{l}\text { Wavenumber of IR spectra } \\
\text { (Meher et al., 2005) }\end{array}$ & Assignment \\
\hline \multirow[t]{7}{*}{0} & 3620 & 3620 & Gibbsite \\
\hline & 3527 & 3521 & Gibbsite \\
\hline & 3488 & 3469 & Gibbsite \\
\hline & 3470 & 3472 & $\begin{array}{l}\text { Stretching } \\
\text { vibration of } \mathrm{OH} \\
\text { Bond }\end{array}$ \\
\hline & 1645 & 1639 & $\begin{array}{l}\text { Bending moments } \\
\text { of } \mathrm{H}_{2} \mathrm{O}\end{array}$ \\
\hline & 1023 & 1072 & $\mathrm{Al}-\mathrm{O}$ bond \\
\hline & 561 & 570 & $\begin{array}{l}\mathrm{Al}-\mathrm{O} \text { stretch } \\
\left(\mathrm{AlO}_{6}\right)\end{array}$ \\
\hline \multirow[t]{2}{*}{$1.0 \times 10^{-4} \mathrm{M}$} & 3465 & 3472 & $\begin{array}{l}\text { Stretching } \\
\text { vibration of } \mathrm{OH}\end{array}$ \\
\hline & 1637 & 1639 & $\begin{array}{l}\text { Bond bending } \\
\text { moments of } \mathrm{H}_{2} \mathrm{O}\end{array}$ \\
\hline \multirow[t]{2}{*}{$4.0 \times 10^{-3} \mathrm{M}$} & 3471 & 3472 & $\begin{array}{l}\text { Stretching } \\
\text { vibration of } \mathrm{OH}\end{array}$ \\
\hline & 1645 & 1639 & $\begin{array}{l}\text { Bond bending } \\
\text { moments of } \mathrm{H}_{2} \mathrm{O}\end{array}$ \\
\hline
\end{tabular}




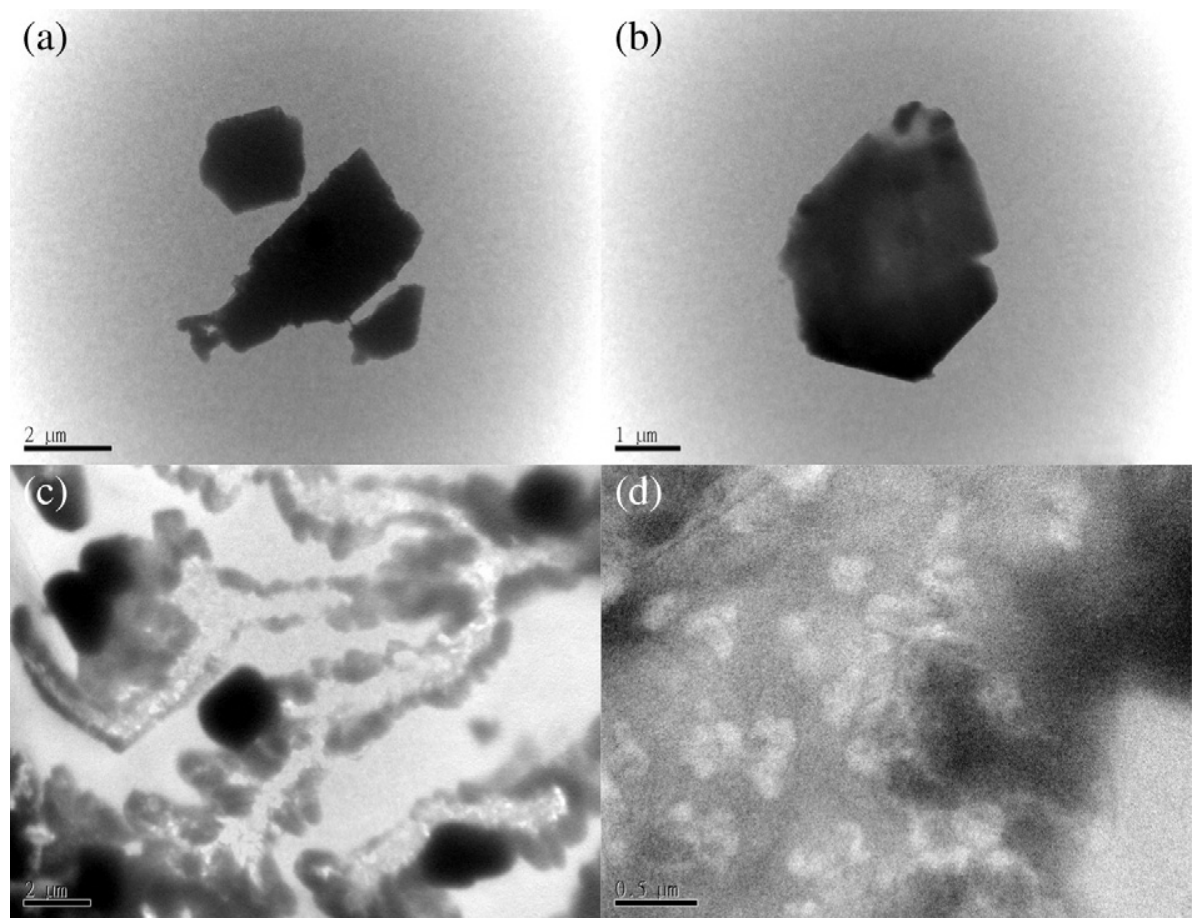

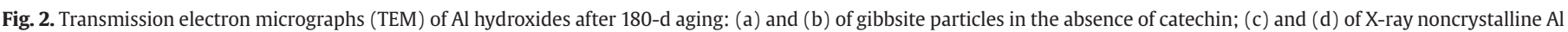
precipitates, in the presence of $4.0 \times 10^{-3} \mathrm{M}$ catechin.

the structural water is not evidenced (Fig. 3c) anymore, but the loss of the adsorbed water is greatly increased.

\section{Discussion}

The influence of catechin on the specific surface area of $\mathrm{Al}$ precipitates is ascribed to the complexation of $\mathrm{Al}$ by catechin and indicated by the stability constant of Al-catechin complexes (Kwong and Huang, 1981). Organic compounds with a molecular weight less

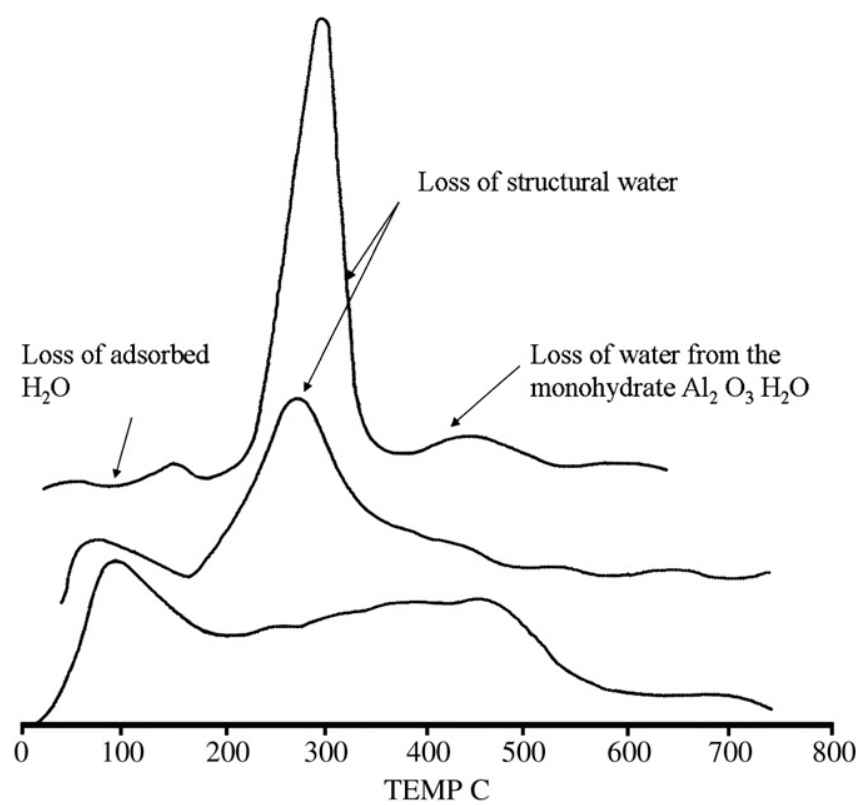

Fig. 3. DTG patterns of Al hydrolytic reaction products: (a) in the absence of catechin, in the presence of (b) $1.0 \times 10^{-4} \mathrm{M}$ catechin and (c) $4.0 \times 10^{-3} \mathrm{M}$ catechin after 180 -d aging. than 150 are not significantly adsorbed by physical forces on the surfaces of clay minerals (Greenland, 1965). In the present study, the catechin's molecular weight is 290.3 , which is related to the physical or chemical adsorption onto $\mathrm{Al}$ precipitates, in addition to the complexation reactions of Al with catechin in the structural network of the precipitates (Table 2). Table 2 demonstrates that nonextractable and precipitated $\mathrm{Al}$ fractions decrease with increasing catechin concentrations, however, the readily and moderately extractable $\mathrm{Al}$ fractions show the reversed trend.

The hydrolytic reaction products of $\mathrm{Al}$ in the absence of interfering ligands have been thoroughly documented in the literature (Hsu and Bates, 1964; Luciuk and Huang, 1974; Kwong and Huang, 1977; Wang et al., 2003; Yu et al., 2007). The X-ray diffractograms show the structural distortion within the hydrolytic reaction products of $\mathrm{Al}$ when catechin is present in the system. This is because catechin can occupy with the coordination sites of Al. This hampers the development of hydroxyl bridging mechanism and also distorts the arrangement of hexagonal units that are present in crystalline aluminum hydroxides.

In the absence of catechin, the polymeric $\mathrm{Al}$ possessed positively charged edges capable of undergoing hydrolysis which leads ultimately to the development of the precipitated crystalline aluminum hydroxides (Kwong and Huang, 1977). Catechin apparently blocks the coordination sites of the terminal-Al through complexation, and thus, hampers the hydroxyl-bridging mechanism in the hydrolysis and polymerization of $\mathrm{Al}$, which is fundamental to the formation of crystalline Al hydroxide precipitates. Therefore, the FT-IR data are in agreement with the XRD data, showing that catechin can inhibit the formation of crystalline aluminum hydroxides.

The degree of the structural distortion of the $\mathrm{Al}$ precipitates increase with increasing initial catechin concentration. The findings from the thermal analysis (Fig. 3) are in agreement with the XRD (Fig. 1), FT-IR (Table 4), TEM (Fig. 2), and SAED data. These findings support the reasoning that catechin hampers the hydroxyl bridging mechanism in the hydrolytic reaction of $\mathrm{Al}$, which is fundamental to the crystallization of $\mathrm{Al}$ hydroxides. 


\section{Conclusions}

X-ray, FT-IR and thermal analyses, and TEM image reveal the fact that structural perturbation of Al precipitation, through complexation and coprecipitation of catechin with $\mathrm{Al}$ results in the formation of short-range ordered $\mathrm{Al}$ precipitates. These $\mathrm{Al}$ precipitates have highly specific surface area, fine, shapeless and hollow colloids which are aggregated. The size of aggregated materials ranges from 0.5 to $2 \mu \mathrm{m}$. The findings obtained in the present study are of fundamental significance in advancing the frontiers of knowledge on low temperature geochemistry and biogeochemistry of $\mathrm{Al}$ and the impact on the environment and ecosystem.

\section{Acknowledgments}

We thank the National Science Council, Taiwan, The Republic of China, for financial support by NSC grants 88-2313-B002-279,892313-B002-279, 90-2213-B002-279 and 92-262-B-002-018.

\section{References}

Bertsch, P.M., Parker, D.R., 1996. Aqueous polynuclear aluminum species. In: Sposito, G (Ed.), The Environmental Chemistry of Aluminum. Lewis Publications, New York, pp. 117-168.

Chen, Y.M., Wang, M.K., Huang, P.M., 2006. Catechin transformation as influenced by aluminum. J. Agric. Food Chem. 54, 212-218.

Cheynier, V., Osse, C., Rigaud, J., 1988. Oxidation of grape juice phenolic compounds in model solutions. J. Food Sci. 53, 1729-1732.

Colombo, C., Ricciardella, M., Cerce, A.D., Maiuro, L., Violante, A., 2004. Effects of tannate, $\mathrm{pH}$, sample properties, aging and temperature on the formation and nature of Al oxyhydroxides. Clays Clay Miner. 52, 721-733.

Dubey, A., Rives, V., Kannan, S., 2002. Catalytic hydroxylation of phenol over ternary hydrotalcites containing Cu, Ni and Al. J. Mol. Catal., A Chem. 181, 151-160.

Greenland, D.J., 1965. Interaction between clays and organic compounds in soils, I. Mechanisms of interaction between clays and defined organic compounds. Soils Fert. 28, 415-425.

Hsu, P.H., 1973. Effect of sulphate on the crystallization of aluminum hydroxide from aging hydroxyl-aluminum solutions. In: Nicolas, J. (Ed.), On Studies of Bauxite and Aluminum Oxides-Hydroxides, pp. 613-620. France.

Hsu, P.H., Bates, T.F., 1964. Formation of X-ray amorphous and crystalline hydroxides. Mineral. Mag. 33, 749-768.

Hu, Y.F., Xu, R.K., Dynes, J.J., Blyth, R.I.R., Yu, G., Kozak, L.M., Huang, P.M., 2008 Coordination nature of aluminum (oxy) hydroxides formed under the influence of tannic acid by X-ray absorption spectroscopy. Geochim. Cosmochim. Acta 72, 1959-1969.
Huang, P.M., 1988. Ionic factors affecting aluminum transformation and the impact on soil and environment sciences. Adv. Soil Sci. 8, 71-78.

Huang, P.M., Wang, M.K., Kämpe, N., Schulze, D.G., 2002. Aluminum hydroxides. In: Dixon, J.B., Schulze, D.G. (Eds.), Soil Mineralogy with Environmental Applications. SSSA Book Series, No. 7. Soil Sci. Soc. Am., Madison, WI, pp. 261-289.

Kim, Y.J., Chung, J.E., Kurisawa, M., Kobayashi, S., 2003. Regioselective synthesis and structure and structures of $(+)$-catechin-aldehyde polycondensates. Macromol Chem. Phys. 204, 1863-1868.

Kodama, H., Schnitzer, M., 1980. Effect of fulvic acid on the crystallization on the crystallization of aluminum hydroxides. Geoderma 24, 195-205.

Kwong, N.G.K.F., Huang, P.M., 1977. Influence of citric acid on the hydrolytic reactions of aluminum. Soil Sci. Soc. Am. J. 41, 692-697.

Kwong, N.G.K.F., Huang, P.M., 1981. Comparison of the influence of tannic acid and selected low-molecular-weight organic acids on precipitation products of aluminum. Geoderma 20, 179-193.

Lim, C.H., Jackson, M.L., 1982. Dissolution of total elemental analysis. In: Page, A. (Ed.) Method of Soil Analysis. Part 2. Soil Science Society of America, Madison, WI, pp. 1-12

Luciuk, G.M., Huang, P.M., 1974. Effect of mono silicic acid on hydrolytic reactions of aluminum. Soil Sci. Soc. Am. J. 38, 235-244.

Meher, T., Basu, A.K., Ghatak, S., 2005. Physicochemical characteristics of alumina gel in hydroxyhydrogel and normal form. Ceram. Int. 31, 831-838.

Roser, P.T., Charlotte, P., Barbara, L., Juan, B., 2005. Aluminium-induced changes in the profiles of both organic acids and phenolic substances underlie Al tolerance in Rumex acetosa L. Environ. Exp. Bot. 54, 231-238.

Sanabria, N., Alvarez, A., Molina, R., Moreno, S., 2008. Synthesis of pillard bentonite starting from the Al-Fe polymeric precursor in solid state, and its catalytic evaluation in the phenol oxidation reaction. Catal. Today 131, 530-533.

Turner, R.C., 1969. Three forms of aluminum in aqueous systems determined by 8 quinolinolate extraction methods. Can. J. Chem. 47, 2521-2527.

Turner, R.C., Ross, G.J., 1970. Conditions in solution during the formation of gibbsite in dilute aluminum salt solution. 4. Effect of $\mathrm{Cl}^{-}$concentration and temperature and a proposed mechanism for gibbsite formation. Can. J. Chem. 48, 723-729.

Vance, G.E., Stevenson, F.J., Sikora, F.J., 1996. Environmental chemistry of aluminumorganic complexes. In: Sposito, G. (Ed.), The Environmental Chemistry of Aluminum. Lewis Publications, New York, pp. 169-220.

Vrsalovic, L., Kliskic, M., Radosevic, J., Gudic, S., 2005. The effect of electrolyte flow rate and temperature on corrosion and protection of $\mathrm{Al}-2.5 \mathrm{Mg}$ alloy by $(+)$-catechin. J Appl. Electrochem. 35, 1059-1065.

Wang, T.S.C., Yeh, K.L., Cheng, S.Y., Yang, T.K., 1971. Behavior of soil phenolic acids. Soil Sci. Soc. Am. J. 32, 113-120.

Wang, S.L., Wang, M.K., Tzou, Y.M., 2003. Effect of temperature on formation and transformation of hydrolytic aluminum in aqueous solutions. Colloids Surf., A Physicochem. Eng. Asp. 231, 143-157.

Whitehead, D.C., 1964. Identification of p-hydroxy-benzoic, vanillic, p-coumaric and ferulic acids in soils. Nature 202, 417-418.

Yu, G., Saha, U.K., Kozak, L.M., Huang, P.M., 2006. Kinetics of cadmium adsorption on aluminum precipitation products formed under the influence of tannate. Geochim. Cosmochim. Acta 70, 5134-5145.

Yu, G., Saha, U.K., Kozak, L.M., Huang, P.M., 2007. Combined effects of tannate and ageing on structural and surface properties of aluminum precipitates. Clays Clay Miner. 55, 369-379. 